\title{
ESFORÇO, FADIGA, DORMÊNCIA: UMA FENOMENOLOGIA POLÍTICA DO CORPO PRÓPRIO NOS PRIMEIROS ESCRITOS DE LEVINAS
}

\author{
Pablo Dreizik \\ Universidad de Buenos Aires
}

Tradução de Klinger Scoralick

\begin{abstract}
RESUMO: Nas análises iniciais do corpo desenvolvidas em De l'existence à l'existant (1937) Levinas dirige sua atenção a um termo próprio do repertório técnico do saber médico: a dormência (engourdissement). Este termo - que não fazia parte do repertório prévio de conceitos da tradição fenomenológica - permite a Levinas realizar uma análise fenomenológica do corpo, que inverte os pressupostos básicos da ideologia do trabalho (Arbeitskraft) dominante nos movimentos políticos extremistas durante o período de entre guerras na Europa. Neste trabalho me ocupo em reconstruir a operatividade do conceito de dormência nos argumentos principais de Levinas, do seu contexto político-cultural e, finalmente, comparar estas análises da dormência com os desenvolvimentos sobre o esforço na obra de Michel Henry.
\end{abstract}

Palavras chave: Levinas, Michel Henry, Dormência, Esforço, Política.

RESUMEN: En los tempranos análisis del cuerpo de desarrollados en De l'existence à l'existant (1937) Levinas dirige su atención a un término propio del repertorio técnico del saber medico: el entumecimiento (engourdissement). Este término -que no formaba parte del repertorio previo de conceptos de la tradición fenomenológica- le permite a Levinas realizar un análisis fenomenológico del cuerpo propio que invierte los supuestos básicos de la ideología del trabajo (Arbeitskraft) dominante en los movimientos políticos extremistas durante el periodo de entreguerras en Europa. En este trabajo me ocupo de reconstruir la operatividad del concepto de entumecimiento en los argumentos principales de Levinas, de su contexto político-cultural y finalmente de contrastar estos análisis del entumecimiento con los desarrollos acerca del esfuerzo en la obra de Michel Henry.

Palabras clave: Levinas, Michel Henry, Entumecimiento, Esfuerzo, Politica. 
Em suas investigações sobre a constituição do sujeito em De l'existence à l'existant ${ }^{1}$ de 1937, Emmanuel Levinas dirige sua atenção aos fenômenos do esforço, da fadiga e da dormência em sua articulação fenomenológica com o corpo próprio. A atenção sobre este domínio particular dos fenômenos corporais corresponde ao seu crescente distanciamento em relação aos desenvolvimentos filosóficos de Heidegger. Em sua estratégia argumentativa, o jovem Levinas oporá o peso e a materialidade da corporeidade - dos quais a fadiga e o esforço são expressão - às noções-chave de Heidegger dos êxtases temporais e da transcendência. Em um nível mais amplo, junto a este propósito programático, De l'existence à l'existant implicará - através, sobretudo, da noção de "fadiga" - uma crítica mais ampla às diversas modalidades daquilo que Anson Rabinbach indicou como a "ideologia produtivista", que nos anos vinte e trinta, na Europa, era compartilhada por um espectro amplo e heterogêneo de ideias, que compreendiam o fascismo, o liberalismo e o nacionalsocialismo alemão. Portanto, a perspectiva de Levinas, não somente colocava em cena o fenômeno da corporeidade - frequentemente observado como ausente nas análises fenomenológicas de Ser e tempo de Martin Heidegger - mas, também, empreendia uma crítica radical às filosofias associadas à exaltação do corpo produtivo - exemplificada, sobretudo, no período de entre guerras, por variações das filosofias vitalistas de Henri Bergson na França e Ludwig Klages ${ }^{3}$ na Alemanha.

Neste contexto, o argumento principal que desejamos indicar em De l'existence à l'existant é a contestação de Levinas à compreensão do esforço humano como um fenômeno que habilita uma certa forma de transcendência ou um "êxtase temporal" - sendo, em troca, o fenômeno do esforço humano, para Levinas, imanente e não

\footnotetext{
${ }^{1}$ Emmanuel Levinas, De l'existence à l'existant, Librairie Philosophique J. Vrin, Paris, 1986 (doravante EE); Emmanuel Levinas, De la existencia al existente, Arena Libros, Madrid, 2000 (doravante DEE).

${ }^{2}$ Anson Rabinbach, The Human Motor: Energy, Fatigue, and the Origins of Modernity, University of California Press, 1992.

${ }^{3}$ Para uma perspectiva filosófica e política do vitalismo de Ludwig Klages ver Nitzan Lebovic, The Philosophy of Life and Death Ludwig Klages and the Rise of a Nazi Biopolitics, Palgrave Macmillan, New York, 2013.
} 
extático. Precisamente, para contestar tal capacidade de transcendência do esforço humano - e, de modo derivado, do "trabalho" - De l'existence à l'existant apresenta as noções de fadiga e dormência. Deste modo, os desenvolvimentos especulativos e fenomenológicos sobre Husserl e Heidegger, que haviam capturado a atenção desses primeiros anos da obra de Levinas, cobram através das análises do esforço, da fadiga e da dormência, um valor político fundamental, como uma crítica radical às diversas ideologias da força do trabalho (Arbeitskraft). Para mostrar as noções de esforço (effort), de fadiga-preguiça-lassidão (fatigue, paresse, lassitude) e de dormência (engourdissement) nos deteremos na crítica ao modelo extático do esforço em De l'existence à l'existant. Logo, contrastaremos esta crítica com a perspectiva de Michel Henry e, por fim, mostraremos a relevância crucial da noção de dormência na argumentação de Levinas.

\section{A crítica ao modelo extático do esforço}

No começo de sua exposição, Levinas evoca um tipo de análise heideggeriana em que o esforço se localizaria "no conjunto de nossas ocupações do dia" ${ }^{\text {. Deste }}$ modo, o esforço poderia situar-se no interior de um horizonte de fins livremente escolhidos: "Se há coação e servidão no esforço essa coação, aparentemente, somente pode ser exterior na medida em que o objetivo por alcançar se impõe à nossa

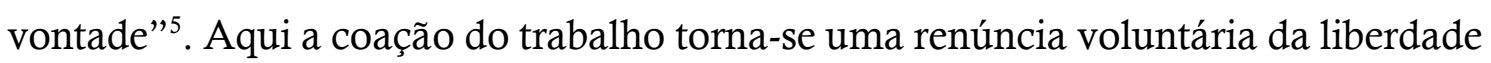
com o propósito de alcançar um fim e criar, assim, um mundo.

\footnotetext{
${ }^{4}$ EE 44/DEE 37. Em Ser e Tempo Heidegger situa o esforço já na dimensão do "ocupar-se": "En el uso circunspectivo de un útil puede ocurrir que digamos, por ejemplo 'el martillo es demasiado pesado o demasiado liviano'. La frase el martillo es pesado puede expresar también una reflexión del ocuparse y entonces significa que no es liviano, es decir que su manejo exige un esfuerzo, que el manejo será difícil" ["No uso circunspectivo de um instrumento pode ocorrer que digamos, por exemplo, 'o martelo é pesado demais ou leve demais'. A frase 'o martelo é pesado' pode expressar também uma reflexão do ocupar-se e, então, significa que ele não é leve, isto é, que seu manejo exige um esforço, que o manejo será difícil"] Martin Heidegger, Ser y Tiempo, trad. Jorge Eduardo Rivera, edit. Editorial Universitaria, Santiago de Chile, 2005, p. 376 (grifo meu).
}

${ }^{5}$ EE 43/DEE 36. 
Entretanto, a argumentação ganha, inesperadamente, uma reviravolta e Levinas passa rapidamente a contestar este esquema explicativo e a sustentar, por outro lado, que no âmbito do trabalho e do esforço não há horizonte de liberdade. Mais ainda, Levinas não esgota seu colocar em questão da liberdade na limitação que a todo esforço impõe sua confrontação com uma resistência. Levinas vai mais além e alega que, na realidade, o que deve ser recusado é a oposição mesma entre ato livre e matéria resistente.

A noção de ato, pressuposta nesta imagem de luta com a matéria, é uma noção que os filósofos se concedem pura e simplesmente. Não se a deduz, isto é, que seu lugar na economia do ser não está assinalado filosoficamente ${ }^{6}$.

Esta contestação da compreensão do esforço e do trabalho humano em termos do dualismo - de ato livre e de matéria resistente - se compreende no âmbito mais geral da recusa fundamental de Levinas ao esquema clássico, que alça a figura do esforço como transcendência, isto é, como um "adiantamento sobre si mesmo e sobre o presente, no êxtase do impulso que queima o presente antecipando-se"7. A via concreta na remoção do caráter transcendente do esforço ocorre pela intervenção do estado de cansaço ou fadiga ${ }^{8}$. O impulso teleologicamente dirigido em direção ao

\footnotetext{
${ }^{6}$ EE 45/DEE 38. Sobre este mesmo ponto, contrapondo a imagem do esforço como dualidade entre impulso e matéria resistente, Levinas acrescenta: "Não é partindo do tema clássico do homem ou do espírito em luta com a matéria ou com o mundo que chegamos à noção de ato e esforço" EE 48/40.

${ }^{7} \mathrm{EE}$ 44/DEE 37 "Dans l'avance sur soi-même et sur soi et sur le présent, dans l'extase de l'élan qui brûle le present en anticipant". Howard Caygill sustenta que Levinas neste período "se desapega radicalmente das análises clássicas de Hegel, Heidegger e Bergson, que compreendem o esforço como orientação criativa ou futura". Howard Caygill, Levinas and the political, Routledge, London-New York, 2002 p. 60 (tradução própria).

${ }^{8}$ Anson Rabinbach explicou o modo como no começo do século XIX a noção de fadiga médica e anímica (astenia) começa a ser percebida como uma ameaça ao interior das filosofias vitalistas e aos modelos econômicos produtivistas. Ver Anson Rabinbach The Human Motor: Energy, Fatigue, and the Origins of Modernity. University of California Press, 1992. Husserl havia incorporado a noção de fadiga ao exame epocal, em chave filosófica, ao referir-se à "Grande Fadiga" do Ocidente (aus dem Vernichtungsbrand del Unglaubens, aus der Asche der grossen Müdigkeit der Phoenix einer neuen Lebensinnerlichkeit und Vergeistgung aufersteht) em Edmund Husserl "Die Krisis des europäischen Menschentums und die Philosophie" Die Krisis des europäischen Wissenschaften und die transzendentale Phänomenologie. Ed. Walter Biemel, La Haya, Martinus Nijoff, 1976, p. 347
} 
futuro do esforço é interrompido por um princípio de atraso, de adiamento, que opera desde sua constituição mesma ${ }^{9}$. Neste sentido, o cansaço - como força inercial que tensiona todo o élan - está sempre já presente no esforço atrasando o impulso, e ao fazê-lo imprime-lhe seu caráter imanente e não extático: "O esforço se levanta a partir do cansaço e recai sobre ele" ${ }^{" 10}$.

Por outro lado, a contestação filosófica que aqui empreende Levinas - através da intervenção do momento do cansaço ou fadiga - do caráter transcendente do esforço e do trabalho, possui um notável alcance crítico em relação às concepções vigentes. Efetivamente, a desconexão radical das noções de trabalho e liberdade - e com isso o colocar em causa de toda perspectiva teleológica do esforço - impõe limite a um pressuposto básico subjacente à modernidade, do qual compartilham, com variações, as concepções de mundo do liberalismo, do socialismo e do fascismo da época. Todas elas assumem que o trabalho se dirige em direção ao futuro e que o futuro está destinado, portanto, a realizar a promessa da liberdade. É por esse motivo que o exame do componente não-intencional do esforço, que empreende Levinas, termina em uma crítica à "mística do trabalho que explora os temas da alegria ou da liberdade mediante o trabalho" 11 .

Para compreender a orientação que imprime Levinas ao movimento do esforço em seu desdobramento é fundamental assinalar que o esforço dirigido ao mundo reenvia a um esforço original: ao "esforço da posição" (l'effort même de la position). A articulação do instante remete ao "esforço da posição" que lhe serve de base: "A referência a si do instante presente é possível mediante a estância a partir

\footnotetext{
${ }^{9}$ EE 44/DEE 37 “(...) el cansancio señala un retraso en relación consigo mismo y con el presente” [“(...) o cansaço assinala um atraso em relação a si mesmo e ao presente"].

${ }^{10}$ EE 44/DEE 37 “L'effort s'elancé de la fatigue et retombe sur elle".

${ }^{11}$ EE 47/DEE 40. No nazismo a exaltação do trabalho como categoria do regime era expressa na criação de organismos como a Amt fur Schönheit der Arbeit ("Oficina para a beleza do Trabalho") e nos desígnios do Arbeit Macht Frei, "o trabalho liberta". Ver Shelley Baranowski Kraft dur Freude. Strenght through Joy: tourism, leisure and consumerism in the Third Reich. Cambridge University Press, Cambridge, 2004.
} 
do lugar" ${ }^{12}$. Neste caso, o esforço assume um caráter imanente, uma vez que na posição o lugar em que se pisa não sustenta o sujeito como uma resistência, senão como uma base, isto é, como condição mesma do esforço. Aqui a posição funciona como contestação do modelo extático heideggeriano: "a pergunta que expusemos a partir da posição consiste precisamente em perguntar-se se o êxtase é o modo original da existência"13. Nesse sentido, a relação com o lugar não seria extática. Enquanto que se pode dizer, por um lado, que o ato se transcende, por outro lado, "o ato da posição não se transcende" ${ }^{14}$.

A importância que Levinas outorga à consideração do esforço extático e imanente em relação ao problema do nascimento da subjetividade é fundamental: "Esse esforço que não se transcende constitui o presente ou o eu"15. Será precisamente a partir desta relação com o lugar como base que se realiza a subjetividade do ente. Não resulta fortuito, portanto, que justamente corresponda à seção dedicada ao esforço sua crítica ao "extatismo do pensamento contemporâneo":

À noção de existência - em que o acento se coloca na primeira sílaba, opomos a noção de um ser cujo próprio advento é um recuo em si, que, em certo sentido, contra o extatismo do pensamento contemporâneo, é uma substância ${ }^{16}$.

Em seu movimento o esforço não se dirige para descobrir a comprovação que ele faz da coisa para a qual se dirige ou contra a qual se exerce, senão a comprovação

\footnotetext{
12 EE 137/DEE 110.

${ }^{13}$ EE 139/DEE 112.

${ }^{14} \mathrm{EE}$ 138/DEE 111.

${ }^{15}$ EE 43/DEE 36.

${ }^{16}$ EE 138/DEE 110. A noção de posição em seu viés não extático, indicada por Levinas, funciona aqui como recusa do caráter extático da ontologia fundamental heideggeriana: "El cuidado heideggeriano, iluminado todo él por la comprensión (incluso si la comprensión misma se da como cuidado), está ya determinado por la estructura 'dentro-fuera' que caracteriza la luz" ["O cuidado heideggeriano, iluminado todo ele pela compreensão (mesmo que a própria compreensão se dê como cuidado), já está determinado pela estrutura 'dentro-fora' que caracteriza a luz"] EE 138/DEE 111. Didier Frank referiu-se a um déficit na consideração da espacialidade nas análises heideggerianas. Ver Didier Franck, Heidegger et le problème de l'espace, Minuit, Paris, 1986.
} 
que ele faz de si. Consequentemente, ao pretender pensar o esforço fazendo abstração de toda formulação intencional, Levinas parece antecipar alguns aspectos da perspectiva de Michel Henry sobre o esforço, para atestar os alcances e pertinência desta comparação.

\section{A perspectiva não-intencional da noção do esforço em Michel Henry}

Em sua intenção de justificar uma compreensão não-intencional e a-mundana da subjetividade, Michel Henry recorre à noção de esforço. Henry pensa o esforço a partir de sua afetividade, de sua imanência a si mesmo. $\mathrm{O}$ argumento principal que aqui se alega é que o movimento que cumpre o esforço, sua superação intencional em direção ao que se coloca como sua resistência, não é a objetivação do poder que se exerce nele:

O que a filosofia chama um processo de objetivação (...) não é jamais possível no sentido em que ela o compreende. Quer se trate do "Espírito", da "Razão", da subjetividade, da consciência ou de qualquer outra instância fundadora, esse processo de objetivação é interpretado como se o poder que realiza a objetivação se objetivasse a si mesmo nela ${ }^{17}$.

Por conseguinte, no esforço dirigido ao mundo o movimento do esforço permanece em si, ao passo que o corpo que realiza o esforço é um corpo, isto é, não é um corpo objetivado deslocando-se no espaço objetivo. Aqui, o exterior - mundo - se dá interiormente - na vida - como uma experiência do esforço, que não tem que transpor nenhuma distância para vir a $\mathrm{si}^{18}$.

\footnotetext{
${ }^{17}$ Michel Henry, Incarnation, une philosophie de la chair, Paris, Le Seuil, 2000, p. 203; Michel Henry, Encarnacion, una filosofia de la carne, trad. Javier Teira; Gorka Fernandez y Roberto Ranz, Editorial Sígueme, Salamanca, 2001, p. 186.

${ }^{18}$ Roberto Walton indica de que modo em Michel Henry a passividade em relação a si depende, não obstante, e em última instância, de um "eu posso" sempre operante e anterior à abertura do mundo transcendente. Roberto Walton "La libertad como destino según Michel Henry" Anuario Colombiano de Filosofia, vol III, agosto 2009.
} 
Este movimento de superação permanece em si e se move em si mesmo, é o automovimento da Vida que se leva consigo na autoafecção patética de sua carne inquebrantável ${ }^{19}$.

Para justificar o caráter imanente e não-intencional do esforço, Henry exemplifica com o caso da mão, que ao exercer seu poder de preensão não realiza nenhum deslocamento objetivo no espaço nem se ultrapassa intencionalmente em direção a nada:

O mover-se desse poder subjetivo de preensão é o movimento que se move em si mesmo e que permanece em possessão de si na imanência de nossa corporeidade originária ${ }^{20}$.

Ao apresentar as descrições do esforço desenvolvidas prematuramente por Levinas junto àquelas que Henry dedicou em Incarnation, sugeri fortes coincidências em pontos centrais. A comparação de ambas perspectivas reforça a hipótese de uma visão compartilhada sobre um núcleo irredutível de autoafecção, sensibilidade imanente localizada no coração do surgimento da subjetividade. Entretanto, será necessário voltar sobre a natureza do movimento que preside a presença do eu a si para vislumbrar decisivas diferenças.

\section{A dormência (engourdissement) como desafecção e distância do eu em relação a si}

Neste texto espero mostrar que a introdução da figura da "dormência" em $D e$ l'existence à l'existant supõe a obtenção de um princípio de distinção que permitirá dar conta do nível de distância que separa os modelos de ipseidade propostos, respectivamente, por Emmanuel Levinas e Michel Henry.

\footnotetext{
${ }^{19}$ Michel Henry, Incarnation, une philosophie de la chair, Paris, Le Seuil, 2000, p. 203-204; Michel Henry, Encarnacion, una filosofia de la carne, trad. Javier Teira; Gorka Fernandez y Roberto Ranz, Editorial Sígueme, Salamanca, 2001, p. 186.

${ }^{20}$ Ibid. p. 205/Ibid. p. 187.
} 
A figura de "dormência" é introduzida por Levinas pela primeira vez na seção "O cansaço e o instante" a propósito de uma discussão ao redor do "esforço" que ocupa essas páginas. Em seu contexto usual o termo "dormência" pertence ao domínio da ciência médica e indica a insensibilidade ou adormecimento em um dos membros do nosso corpo ${ }^{21}$. Levinas ao fazer uso deste termo da linguagem médica se dirige, de modo direto, a complexificar a questão do esforço como autoafecção e evidência de si. Em primeiro lugar, a dormência introduz de maneira decisiva o momento de uma desafecção por dessensibilização, interrompendo o curso de afecção que o eu mantém consigo mesmo no esforço. Ao colocar-se assim em jogo a instância de uma desafecção ou dessensibilização, a evidência de si como autoafecção, que se cumpre no esforço, fica alterada por um desvio ou descompasso (décalage). Por esse motivo Levinas pode afirmar que a "dormência do cansaço" é tanto uma "impossibilidade de seguir" como, também, um desvio constante e crescente (décalage constant et croissant) ${ }^{22}$ - mais ainda, o fenômeno da dormência não se agrega ao esforço como um fenômeno de acompanhamento cinestésico, mas sim, se encontra constitutivamente ligado a ele. Portanto, o começo do esforço, o instante da subjetivação do existente, se vê desviado por uma desafecção que dispõe de uma distância que desajusta a presença do eu frente a si mesmo ${ }^{23}$. Deste modo, a fadiga comporta uma perda de sensibilidade que invade desde o começo o esforço. Articulando, novamente, figuras de um domínio semântico das ciências médicas, Levinas se refere a esse desvio como uma "luxação" (luxation), no sentido daquilo que sempre complica originalmente o esforço em sua identidade afetiva consigo

\footnotetext{
${ }^{21}$ A dormência como perda de sensibilidade - junto a sintomas de formigamento - pertence aos sintomas gerais dos quadros médicos de parestesia.

${ }^{22}$ EE 42/DEE 36.

23 "Desfase del ser en relación consigo mismo (décalage de l'être par rapport à lui-même), que destacamos como la característica principal del cansancio" ["Desvio do ser em relação a si mesmo (décalage de l'être par rapport à lui-même), que destacamos como a característica principal do cansaço"] EE 43/DEE 35-36.
} 
mesmo: o esforço "desarticulado de si - em uma luxação do eu consigo mesmo não se reunifica no instante" ${ }^{24}$.

Como se pode ver, trata-se aqui da intervenção de uma instância de desafecção ou suspensão da sensibilidade afetiva. É esta desafecção que em realidade se mostra como a condição mesma de possibilidade da subjetividade: "Em sua simplicidade e em sua unidade e em sua obscuridade de cansaço este é como um atraso (retard) que o existente conduz ao existir" e, acrescenta Levinas, "este atraso constitui o presente (...) graças a essa distância a existência é relação entre um existente e ela mesma" 25 . O momento da dormência - sendo ele um "esgotamento ou envenenamento muscular" - é, de modo paradoxal, enquanto de-sensibilização ( $\alpha \pi$ - $\alpha \iota \sigma \theta \eta \tau \iota \kappa о \pi о$ $\eta \sigma \eta)$, possibilidade de subjetividade. A lógica pela qual a suspensão ou interrupção da afetividade se torna condição de individuação, aproxima-se do esquema de interiorização do nada como condição de uma subjetividade "para si" em Sartre, bem como à ideia de de-sensibilização ou desensorialização (desensitization) ${ }^{26}$ dos sentidos em relação ao mundo nos trabalhos tardios de Hannah Arendt. Em ambos os casos é a distância afetiva do eu com relação a si - como "descompressão do ser" (décompression d'être) em Sartre ou "desensorialização" em Arendt - que habilita a possibilidade da subjetivação.

Resulta, assim, que a descrição do cansaço aparece como um operador fenomenológico que permite tornar inteligível o modo ambíguo em que se mantém a subjetividade como um movimento alternante de apropriação e desapropriação de si. Um exemplo de Levinas pode ilustrar a orientação ambígua atribuída a este movimento. O cansaço do esforço é um "desvio constante e crescente do ser em

\footnotetext{
24 "Désarticulé de soi, - dans une luxation du moi par rapport à soi" ["Desarticulado de si, - em uma luxação do eu em relação a si”] EE 50/42.

${ }^{25} \mathrm{EE} 51 / 42$.

${ }^{26}$ Hannah Arendt, La vida del espiritu, trad. Fina Birules y María Corral, Paidós, Barcelona, p. 109. Ver também p. 99. Para Arendt a "operação de dessensorialização" é a condição do pensamento como retirada do mundo das aparências. Certamente, esta perspectiva inspira-se nos desenvolvimentos dos filósofos hedonistas-cirenaicos. Ver (Michael Gagarin, Elaine Fantham edt. ) The Oxford Encyclopedia of Ancient Greece and Rome, Volumen I. Oxford University Press, 2010, p. 274.
} 
relação isso a que permanece atado" ${ }^{27}$. E no mesmo sentido, mais adiante, afirma ainda que não se trata de "uma mão que solta o peso que sustenta pelo cansaço, mas sim de uma mão que se sujeita aquilo que solta"28.

a) Por um lado, o cansaço do esforço é condenação ao ser, condenação da presença ao seu próprio peso de ser, um "empenho irremissível, sem possibilidade de resgate" - sem que a condenação da servidão advenha desde fora, como imposta por um amo, pois mesmo no trabalho eleito de modo o mais livre, o esforço mesmo comporta um castigo. O cansaço do esforço é condenação, uma vez que "assume o instante como um presente inevitável". Enquanto condenação ao ser, o esforço é uma impossibilidade de escapar a si e não dá ao eu o poder de se esquivar de sua própria presença. Aqui a condenação do esforço, em sua subjetividade radical, não extática e imanente, coincide com as análises de Michel Henry do esforço como impossibilidade de fugir de si, "pas d'échappatoire possible". Neste primeiro sentido, a análise de Levinas da estrutura da subjetividade pela via da fadiga se aproximaria da perspectiva de Henry ao considerar a presença do eu consigo mesmo em termos de "passividade radical em relação a si, enquanto inundado e submergido por seu próprio peso" ${ }^{29}$.

b) Entretanto, e de maneira contrária aos pressupostos da "fenomenologia material" de Henry, a análise da noção de fadiga ou cansaço que empreende Levinas, revela na estrutura da subjetividade uma modalidade de desafecção permanente. Este segundo aspecto é enfatizado em De l'existence à l'existant

\footnotetext{
${ }^{27}$ EE 42/DEE 35-36.

${ }^{28}$ EE 42/DEE 36. É importante assinalar, juntamente com Rodolphe Calin, que aqui o "relaxamento" - relâchement - não diz respeito somente à mão objetiva que aflora ou distende um objeto do mundo, mas também à evidência subjetiva que ela tem de seu poder de preensão. Ver Rodolphe Calin, Levinas et l'exception du soi, Presses Universitaires de France, 2005, p. 112.

${ }^{29}$ Michel Henry, Phenomenologie materielle, Edit. PUF, Paris, 1990, p. 177 (tradução própria).
} 
através, precisamente, da figura do "enrijecimento (raidissement), um ressecamento (dessèchement), uma ruptura com as fontes vivas" ${ }^{30}$. A fadiga é, nesse sentido, uma esquiva (esquive) ou uma hesitação diante da presença a si do eu, isto é, uma perda de presença diante de si. Neste segundo aspecto, o mover-se desse poder do esforço não corresponde a um movimento que, como em Henry, "movendo-se em si mesmo" coincidirá em cada ponto de seu ser consigo mesmo, mas com um movimento que se evidencia em sua não coincidência consigo mesmo.

${ }^{30} \mathrm{EE} 50 / 42$. 